\title{
E1A stimulates FGF-2 release promoting differentiation of primary endothelial cells
}

\author{
C Giampietri ${ }^{1,6}$, M Levrero $^{2,3}$, A Felici $^{1,5}$, A D'Alessio ${ }^{4}$, \\ MC Capogrossi ${ }^{1}$ and C Gaetano ${ }^{\star, 1}$ \\ ${ }^{1}$ Laboratorio di Patologia Vascolare, Istituto Dermopatico dell'Immacolata, \\ Istituto di Ricovero e Cura a Carattere Scientifico, 00167 Rome, Italy \\ 2 Laboratorio di Espressione Genica, Fondazione Andrea Cesalpino, Università \\ degli Studi di Roma "La Sapienza", 00161 Rome, Italy \\ ${ }^{3}$ Istituto di Medicina Interna, Università di Cagliari, 09124 Cagliari, Italy \\ 4 Dipartimento Istologia ed Embriologia Medica, Università degli Studi di Roma \\ "La Sapienza", 00161 Rome, Italy \\ ${ }^{5}$ Laboratory of Cellular and Molecular Biology, National Cancer Institute, NIH, \\ Bethesda, MD 20892-4255, USA \\ ${ }^{6}$ Current address: Dipartimento Istologia ed Embriologia Medica, Università \\ degli Studi di Roma "La Sapienza", 00161 Rome, Italy. E-mail: \\ giampietri@uniroma1.it \\ * Corresponding author: C Gaetano, Laboratorio di Patologia Vascolare, Istituto \\ Dermopatico dell'Immacolata, Via dei Monti di Creta, 104, 00167 Rome, Italy. \\ Tel: 39-06-66464794; 39-06-66462433; Fax: 39-06-66462430; E-mail: \\ gaetano@idi.it
}

Received 29.7.99; revised 4.11.99; accepted 10.12.99

Edited by $\mathrm{C}$ Thiele

\begin{abstract}
Basic Fibroblast Growth Factor (FGF-2) is a growth and survival factor and represents one of the most potent differentiation agents of vascular system. In the present study we describe that adenoviral oncoprotein $E 1 A$ regulates FGF-2 production and determines the acquisition of a proangiogenic phenotype in primary bovine aortic endothelial cells (BAEC). Following their transfection, wild type E1A proteins $12 S$ and $13 S$ (wtE1A) stimulated BAEC to differentiate on reconstituted basement membrane matrix (Matrigel). This outcome was paralleled by invasion and migration enhancement in wtE1A-transfected cells. This stimulating effect was absent with the E1A mutant dI646N. Accordingly, zymography and RT - PCR analyses showed that matrix metalloproteinase9 protein- and mRNA-levels increased following wtE1A transfection. Interestingly, wtE1A-transfected BAEC showed FGF-2 mRNA-and protein-levels higher than controls. Further, FGF-2 neutralization reduced the amount of MMP-9 released in the supernatant of E1A-transfected cells and strongly inhibited BAEC differentiation, thus suggesting that wtE1A activates BAEC by a mechanism, at least partially, dependent on a FGF-2 autocrine/paracrine loop. Cell Death and Differentiation (2000) 7, 292-301.
\end{abstract}

Keywords: angiogenesis; E1A; FGF-2; matrix metalloproteinase; endothelial cell; differentiation

Abbreviations: BAEC, primary bovine aortic endothelial cells; TS, tubular structures; $\mathrm{CM}$, conditioned medium; $\mathrm{EC}$, endothelial cells; $\mathrm{E} 1 \mathrm{~A}$, product of early region 1 of adenovirus genome; FGF-2, basic fibroblast growth factor; MMP-9, matrix metalloproteinase 9; $\mathrm{R}$, aminoacid residues; wtE1A, wild type E1A $12 S$ and wild type E1A 13S; LMW, low molecular weight; HMW, high molecular weight; DMEM, Dulbecco's modified Eagle's medium

\section{Introduction}

Differentiation of vascular cells in new blood vessels, or angiogenesis, occurs in physiological conditions such as the menstrual cycle and pregnancy as well as during pathological processes including growth of primary tumors and metastasis, wound healing and ischemia. Angiogenesis proceeds through a series of steps schematically summarized as follows: (a) degradation of extracellular matrix, (b) endothelial cells (EC) migration, (c) invasion and proliferation and, finally, (d) reestablishment of cell-to-cell contacts and lumen formation. ${ }^{1-3}$

This process is modulated by a balance of positive and negative stimuli provided by growth factors and by EC interaction with extracellular matrix components. ${ }^{4-8}$ Local production of angiogenic factors including vascular endothelial growth factors (VEGFs), fibroblast growth factors (FGFs) and platelet-derived growth factors (PDGFs), have been shown to guide EC toward their organization in new vascular structures. $^{9-13}$ The FGF-2 member of the FGF family is known as a potent growth, survival and differentiation factor; it exists in five distinct isoforms: the low molecular weight $18 \mathrm{kDa}(\mathrm{LMW})$ and the high molecular weight 22, 22.5, 24 and $34 \mathrm{kDa}(\mathrm{HMW}){ }^{14-16}$ The LMW isoform is the most abundant secreted type of FGF-2 and acts through a specific tyrosine kinase receptor binding and internalization process. ${ }^{17-21}$ FGF-2 lacks a signal peptide and is exported outside the cell via a poorly characterized alternative pathway. ${ }^{22-24}$ FGF-2 has been shown to modulate several functions of vascular cells including survival, differentiation, migration and invasion ${ }^{25-28}$ but, despite the large interest, mechanisms controlling FGF-2 production need to be further clarified. Interestingly, several studies reported that the expression of some viral oncoproteins in cultured cells may stimulate their proliferation, partially mimicking growth factors activity. ${ }^{29-32} \mathrm{E} 1 \mathrm{~A}$, the product of the adenovirus early region 1 , is multifunctional with respect to immortalizing functions, trans-activating properties of viral and cellular genes and induction of apoptosis. E1A splicing isoforms $12 \mathrm{~S}$ and 13S, coding for the 243 aminoacid residues $(R)$ and the $289 R$ proteins, respectively, contain the conserved regions named CR1 and CR2. The $46 R$ CR3 domain is present only in E1A $13 S$ and it seems to be required for the transcription of early viral genes and for the transactivation of different viral and cellular promoters. ${ }^{33,34} \mathrm{E} 1 \mathrm{~A}$ has been reported to interact with different classes of intracellular molecules interfering with their functions. ${ }^{35-40}$ Specifically, E1A isoforms are known to associate with cyclin $A$, with the product of the retinoblastoma susceptibility gene (pRb), with other members 
of this family, and with the 300-kDa (p300) and 400-kDa (p400) transcriptional adapters. ${ }^{41-47}$ These proteins are usually inactivated or deregulated as a consequence of E1A interaction, leading to different biological effects including induction of DNA synthesis, mitosis and apoptosis. ${ }^{48,49}$ Since forced expression of E1A has been shown to induce growth factors release,$^{50-52}$ we investigated whether its overexpression in bovine aortic endothelial cells (BAEC) affected their differentiation properties. Our results show that $\mathrm{E} 1 \mathrm{~A} 12 \mathrm{~S}$ and $13 \mathrm{~S}$ activate a process characterized by enhanced differentiation into tubular structures, increased motility, invasivity and gelatin-degrading activity. Such effects were associated with increased FGF-2 production.

\section{Results}

\section{E1A enhances BAEC differentiation on Matrigel}

BAEC plated on reconstituted basement membrane matrix (Matrigel) stop their proliferation and differentiate into tubular

A
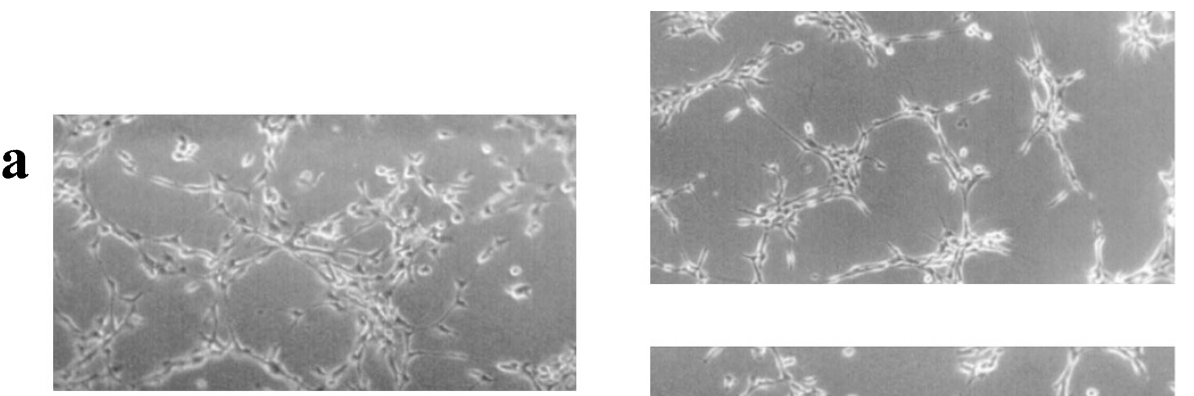

c

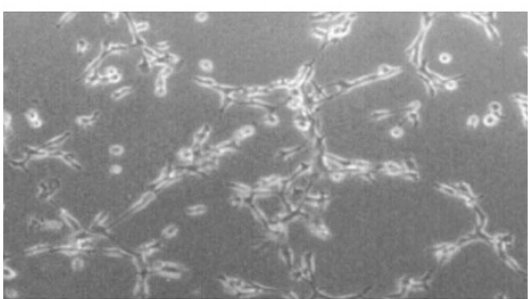

d
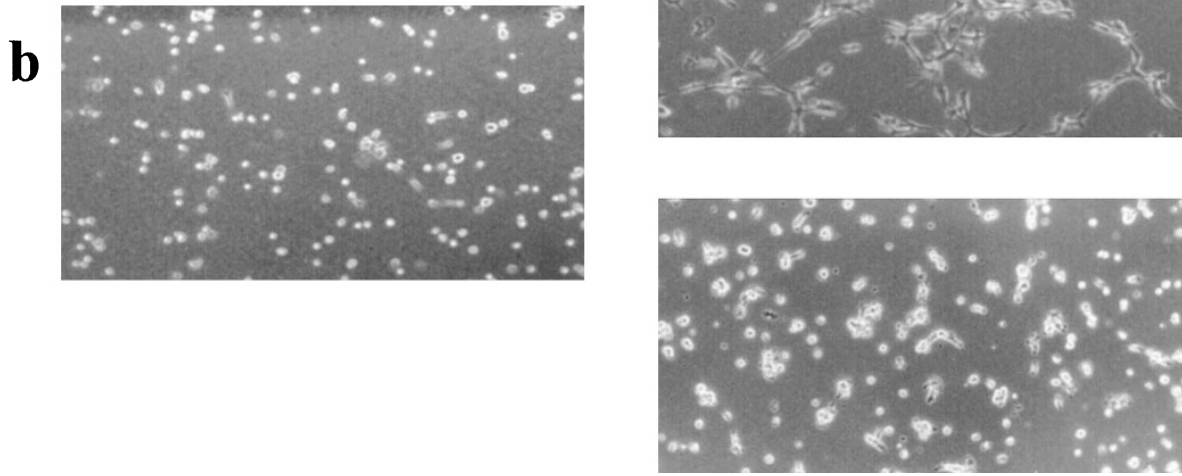

$\mathbf{e}$

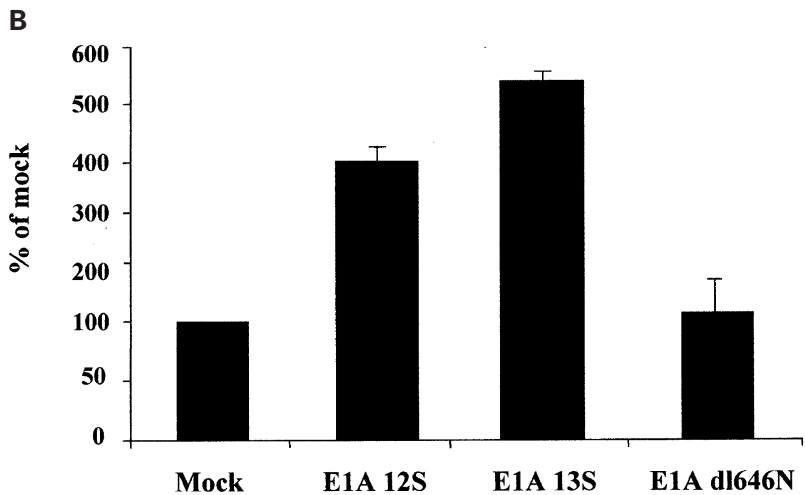

Figure 1 Effect of E1A on BAEC TS formation. (A) Micrographs of transfected BAEC plated on Matrigel. Mock, E1A 12S, E1A 13S and E1A dl646N-transfected BAEC were plated on Matrigel $48 \mathrm{~h}$ after transfection and cultured in DMEM containing $10 \% \mathrm{FCS}$ as described in Materials and Methods. Pictures taken $3 \mathrm{~h}$ after plating show TS development in E1A 12S-transfected cells (panel c) and in E1A 13S-transfected cells (panel d). E1A dl646N (panel e) and mock transfected cells (panel b) did not show any TS formation at the same time point. Mock transfected cells, in the same conditions (panel a) developed TS $8 \mathrm{~h}$ after plating. Magnification $100 \times$. (B) Quantification of TS formed by E1A-transfected BAEC after plating on Matrigel. Cells were seeded on Matrigel $48 \mathrm{~h}$ after transfection, in the presence of DMEM with $10 \% \mathrm{FCS}$ and TS were counted by phase contrast microscopy using a $100 \times$ magnification. TS formation, measured $3 \mathrm{~h}$ after plating, revealed a significant increase for E1A 12S and E1A $13 S$ compared to mock and E1A dl646N-transfected cells $(P<0.05)$. Differences between E1A dl646N and mock transfected cells were not statistically significant. Results represent the average of four independent experiments and are expressed as mean $\pm S$.E. 
structures (TS), ${ }^{53}$ partially recapitulating the process of new blood vessel formation occurring in vivo. ${ }^{54}$ In order to investigate the effects of $E 1 A$ on TS organization on Matrigel, BAEC were transfected with various expression vectors coding for E1A 13S, E1A 12S and the CR1 domaindeleted protein E1A dl646N. Transfection efficiency reached approximately $30 \%$ and transgene expression was confirmed by Western blot analysis $48 \mathrm{~h}$ after transfection (not shown). Differentiation assays on Matrigel were carried out $48 \mathrm{~h}$ after transfection and were performed in medium containing $10 \%$ fetal calf serum (FCS). Preliminary signs of TS formation occurred in E1A 12S and E1A 13S-transfected cells as soon as $3 \mathrm{~h}$ after plating (Figure $1 \mathrm{~A}$, panel $\mathrm{c}$ and $\mathrm{d}$ ). Conversely, $\mathrm{E} 1 \mathrm{~A}$ dl646N and mock transfected cells were not organized at $3 \mathrm{~h}$ (Figure 1A, panels e and b) and formed TS $8 \mathrm{~h}$ after plating (Figure 1A, panel a). As shown in Figure 1B, TS quantification $3 \mathrm{~h}$ after plating revealed 4-6-fold increase for E1A $12 S$ and E1A 13S-transfected cells, respectively, as compared to mock transfected cells cultured in the same conditions. These experiments indicated that wtE1A specifically accelerated TS formation on Matrigel in vitro.

\section{E1A stimulates EC invasion and migration}

Since EC organization in new vessels depends on their ability to migrate and invade extracellular matrix, ${ }^{55} \mathrm{E} 1 \mathrm{~A}$-transfected BAEC invasion and migration were evaluated in a modified Boyden chamber assay, $48 \mathrm{~h}$ after transfection. Invasion assays were performed on Matrigel-coated filters and revealed that $\mathrm{E} 1 \mathrm{~A} 12 \mathrm{~S}$ and $\mathrm{E} 1 \mathrm{~A}$ 13S-transfected cells invaded $51 \%$ and $40 \%$ more than control, respectively (34 cells/field in mock transfected cells on average) (Figure 2A). In contrast, the dl646N mutant did not stimulate BAEC invasion. Migration assays on uncoated filters (Figure 2B) showed that migration of E1A $12 S$ and 13S-transfected cells was 3-3.5-fold higher than E1A dl646N or mock transfectants (45 cells/field in mock experiments on average). These results indicated that typical features of the angiogenic phenotype such as invasion and migration were specifically stimulated by wtE1A.

\section{E1A increases FGF-2 mRNA and stimulates secretion of the $18 \mathrm{kDa}$ isoform from transfected BAEC}

In order to investigate whether angiogenic factors were involved in the observed modulation of EC functions, FGF-2 and VEGF release was evaluated. ELISA assays revealed a significant increase of FGF-2 levels in CMs collected from E1A 12S and E1A 13S-transfected cells compared to the CMs from mock and E1A dl646N-transfected cells. Figure $3 \mathrm{~A}$ shows FGF-2 levels in CMs collected after $24 \mathrm{~h}$ incubation in serum free condition, $60 \mathrm{~h}$ from transfection. FGF-2 levels were $11 \pm 5$ and $17 \pm 1 \mathrm{pg} / 10^{5}$ cells $/ 24 \mathrm{~h}$ in CMs from $\mathrm{E} 1 \mathrm{~A}$ $12 S$ and E1A 13S-transfected cells, respectively, while they were markedly lower in CMs from E1A dl646N $\left(1 \pm 0.5 \mathrm{pg} / 10^{5}\right.$ cells $/ 24 \mathrm{~h})$ and mock transfected cells $\left(0.22 \pm 0.1 \mathrm{pg} / 10^{5}\right.$ cells/24 h). Conversely, ELISA assay for VEGF indicated that this factor was not induced by $E 1 A$ (data not shown). Western blot analysis on CMs from E1A-transfected cells showed that E1A 12S and E1A 13S induced the secretion of the $18 \mathrm{kDa}$ FGF-2 LMW isoform (Figure 3B), while the high molecular weight (HMW) isoforms were not detected. Conversely, both LMW and HMW isoforms were present in whole cell extracts from transfected cells but they did not appear modulated (Figure 3C). Northern blot analysis indicated that in the presence of wtE1A the FGF-2 steady state mRNA level increased 3-5-fold compared to mock or dl646N-transfected cells (Figure 3D). Taken together these results indicated that wtE1A expression in BAEC modulated FGF-2 mRNA and protein production.

\section{E1A increases MMP-9 mRNA level and protein secretion}

A correlation between FGF-2 levels and production of matrixdigesting enzymes has been described in EC. ${ }^{56}$ Therefore, it was determined whether E1A expression increased matrix

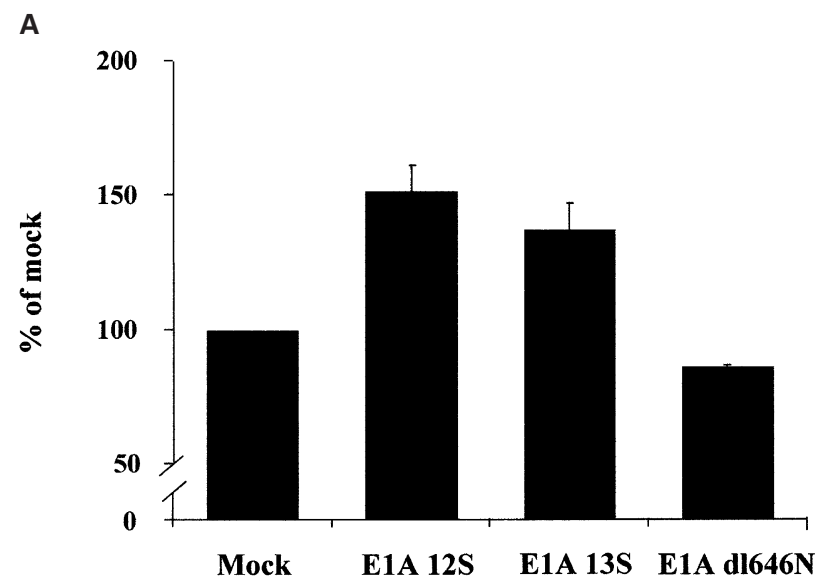

B

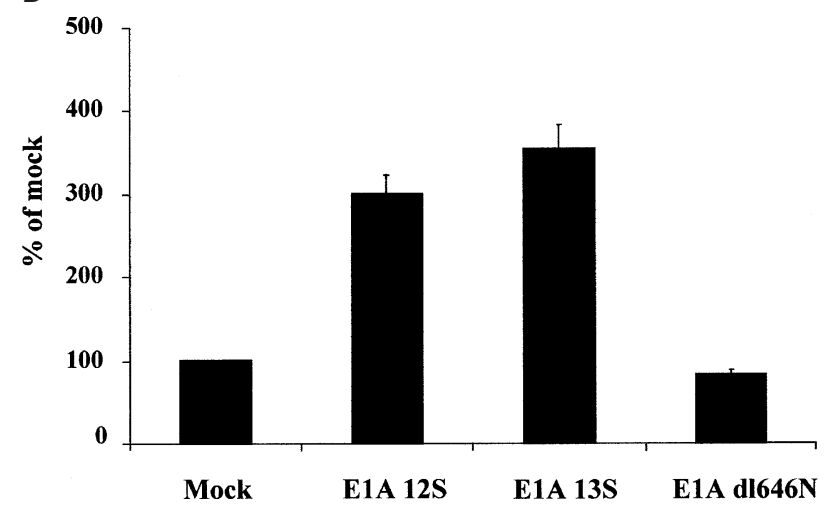

Figure 2 E1A effect on BAEC invasion/migration. (A) Quantitative evaluation of BAEC invasion through Matrigel-coated filters $48 \mathrm{~h}$ after E1A transfection. wtE1A-transfected cells showed invasiveness significantly higher $(P<0.05)$ than $d 1646 \mathrm{~N}$ and mock transfected cells. Results represent the average of three different experiments performed in triplicate and are expressed as mean \pm S.E. (B) Quantitative evaluation of BAEC migration through uncoated filters $48 \mathrm{~h}$ after transfection. wtE1A-transfected cells showed migration significantly higher than dl646N and mock transfected cells $(P<0.05)$. Migratory ability of E1A dl646N-transfected cells was comparable to control. Results represent the average of three different experiments in triplicate and are expressed as mean \pm S.E. 
A

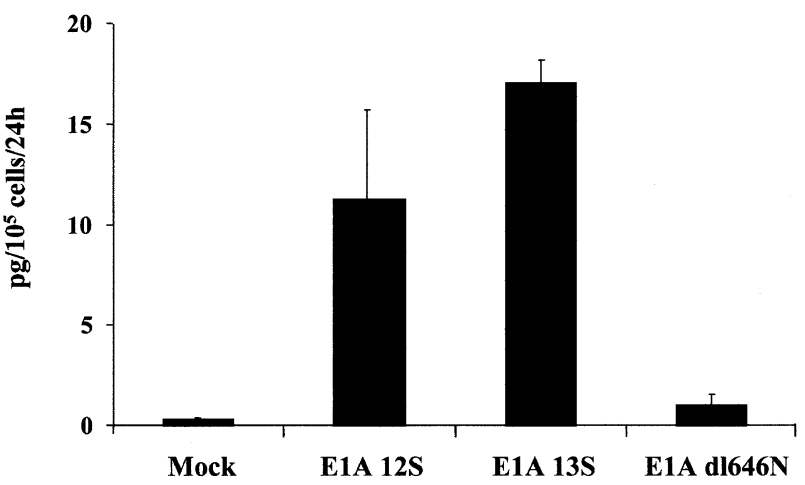

B

\section{KDa}

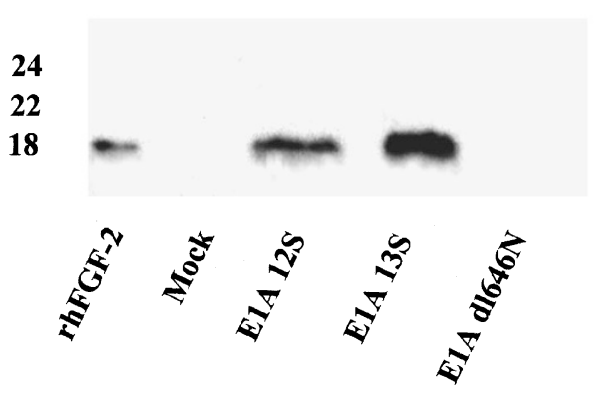

KDa

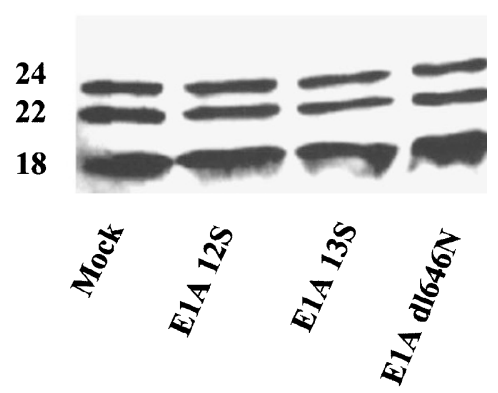

D

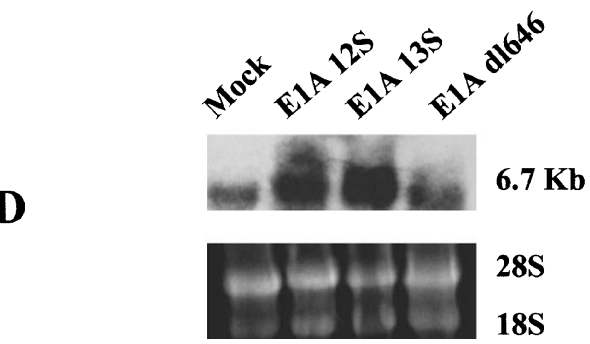

C

Figure 3 E1A induces FGF-2 production. (A) ELISA measurement of FGF-2 in E1A-transfected cells CMs. The graph shows the production of FGF-2, evaluated by ELISA, detected in E1A-transfected BAEC CM. Cells were cultured in serum-free medium for $24 \mathrm{~h}$ and CMs were collected $60 \mathrm{~h}$ after transfection. CMs were concentrated tenfold and assayed for the presence of FGF-2 by ELISA. Data were normalized for cell number and show a significant increase of FGF-2 production in samples from E1A 12S and E1A 13S-transfected cells, as compared to samples obtained from mock and E1A di646N-transfected cells $(P<0.05)$. Results represent the mean + S.E. of three independent experiments. (B) Western blot analysis of FGF-2 released in CMs collected from E1A-transfected cells. E1Atransfected cells were cultured in serum-free medium for $24 \mathrm{~h}$, and CMs were collected $60 \mathrm{~h}$ after transfection. CMs were concentrated and immediately assayed for FGF-2. Samples were normalized for cell number. The $18 \mathrm{kDa}$ FGF-2 isoform was found in E1A 12S and E1A 13S-transfected cells CMs while it was absent in CMs from mock and E1A dl646N-transfected cells. The positive control corresponding to recombinant human $18 \mathrm{KDa}$ FGF-2 (rhFGF-2) is also shown. (C) Western blot analysis of FGF-2 in whole cell extracts from E1A-transfected BAEC. Each lane was loaded with lysate from $10^{5} \mathrm{cells}, 48 \mathrm{~h}$ from transfection. The HMW isoforms of 22 and $24 \mathrm{kDa}$ as well as the LMW isoform of $18 \mathrm{kDa}$ were found in all the samples and appeared not modulated. (D) Northern blot analysis of FGF-2 in total RNA from E1A-transfected cells. Twenty micrograms of RNA were loaded in each lane. A single FGF-2 mRNA band (6.7 Kb) was revealed in all samples and it appeared markedly increased in E1A $12 \mathrm{~S}$ and E1A 13S-transfected cells if compared to E1A dl646N and mock transfected cells. Ribosomal RNAs $28 \mathrm{~S}$ and $18 \mathrm{~S}$ are also shown

metalloproteinases production. CMs were collected after $24 \mathrm{~h}$ incubation in serum-free medium, $60 \mathrm{~h}$ after transfection and gelatin-degrading proteinase activity was assayed. The zymographic analysis showed the presence of matrix metalloproteinase 9 (MMP-9) in CMs collected from E1A $13 S$ and E1A 12S-transfected cells while MMP-9 was absent in both $\mathrm{E} 1 \mathrm{~A}$ d $1646 \mathrm{~N}$ and mock transfected cells (Figure 4A). Densitometric analysis also indicated that wtE1A transfection increased MMP-2 levels approximately 30\% as compared to both E1A dl646N and mock transfected cells (not shown). To further investigate E1A regulation of MMP-9 production, RTPCR was performed to evaluate the mRNA expression (Figure 4B). Bovine MMP-9 mRNA was induced in BAEC transfected with E1A $12 S$ and E1A $13 S$ whereas MMP-9 mRNA was barely detectable in E1A dl646N and absent in mock transfected cells. Finally, the effect of anti-FGF-2 
A

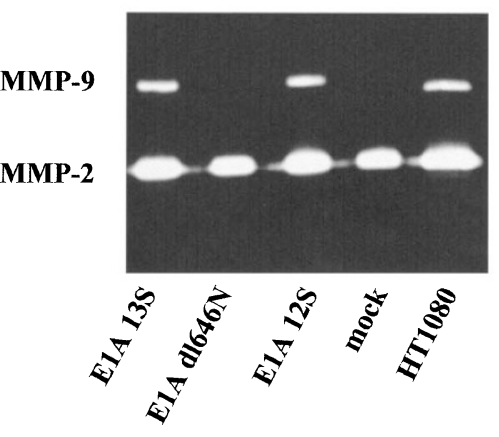

B

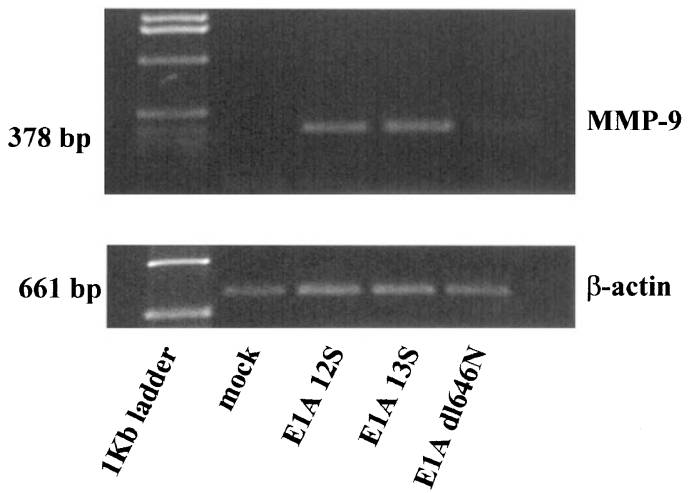

$\mathbf{C}$

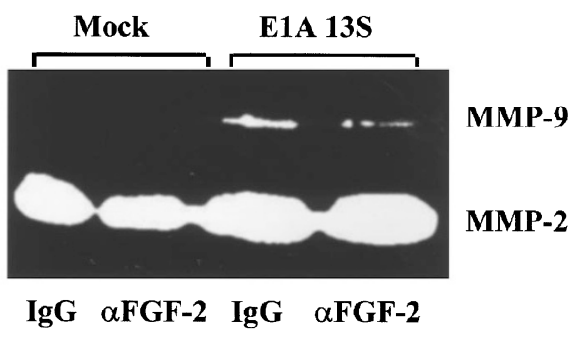

Figure 4 E1A effect on BAEC MMP-9 production. (A) Zymography assay. E1A-transfected cells were cultured in serum free medium for $24 \mathrm{~h}$ and $\mathrm{CMs}$ were collected $60 \mathrm{~h}$ after transfection. CMs were then immediately assayed for the presence of matrix metalloproteinases by zymography. Samples were normalized for cell number. MMP-2 gelatin degrading activity was found in all samples tested while MMP-9 gelatin degrading activity was present only in samples collected from E1A 13S and E1A 12S-transfected cells as well as in samples from HT1080 cells, used as positive control. A representative example of four different experiments is shown. (B) RT - PCR analysis. MMP-9 mRNA levels were evaluated by RT-PCR analysis using total RNA extracted from BAEC $48 \mathrm{~h}$ after E1A transfection. MMP9 mRNA was induced by transfection with E1A 12S and E1A 13S while it was barely detectable in E1A dl646N and in mock transfected cells. The amount of loaded mRNA was similar in all lanes as indicated by $\beta$-actin co-amplification. A similar result was obtained in three independent experiments. (C) Zymography analysis. The picture shows a zymography performed as in (A) analysing CMs from E1A $13 \mathrm{~S}$ and mock transfected cells exposed to control antibodies (IgG) or neutralizing anti-FGF-2 antibodies during the $24 \mathrm{~h}$ incubation in serum free medium. A reduction of about $50 \%$ of MMP-9 produced by E1A $13 \mathrm{~S}$-transfected cells was detected in the presence of anti-FGF-2 antibodies

neutralizing antibodies or control antibodies was analyzed in a series of zymographic assays. Figure $4 \mathrm{C}$ shows that wtE1Atransfected cells, in the presence of neutralizing anti-FGF-2 antibodies, produced markedly less MMP-9 (about 50\% less) as compared to wtE1A-transfected cells in the presence of control antibodies. These results indicated that E1A expression increased MMP-9 protein and mRNA levels. This process might be at least in part dependent on biologically active FGF-2.

\section{E1A induction of BAEC differentiation depends on secreted FGF-2}

In these experiments it was examined whether the enhanced BAEC organization on Matrigel following E1A 13S-transfection was FGF-2 dependent. Neutralizing antiFGF-2 monoclonal antibodies were added to wtE1Atransfected cells plated on Matrigel. Figure 5 shows pictures taken $24 \mathrm{~h}$ after plating on Matrigel in the presence of medium supplemented with $1 \%$ serum, a condition per se not efficiently supporting EC differentiation in our experimental conditions. TS formation in wtE1A- transfected cells was evident in the presence of control antibodies (Figure $5 \mathrm{~b}$ ) while it was completely inhibited by addition of neutralizing anti-FGF-2 antibodies (Figure 5e). Mock transfected cells differentiated poorly in $1 \%$ FCS alone (not shown) or in the presence of control antibodies (Figure $5 \mathrm{~d}$ ). TS formation in $1 \%$ serum and $10 \mathrm{ng} / \mathrm{ml}$ recombinant FGF-2 is shown for mock transfected cells (Figure $5 \mathrm{C}$ ) and it was completely inhibited in the presence of neutralizing anti-FGF-2 antibodies (Figure 5f). As control, TS formation in $10 \%$ serum for mock transfected cells is also shown (Figure 5a). These results supported the hypothesis that wtE1A-induced EC differentiation depends on biologically active FGF-2.

\section{Discussion}

A large number of secretory, membrane-bound and intracellular molecules regulate EC response to a variety of angiogenic stimuli. ${ }^{57}$ Interestingly, several oncogenes were found to stimulate angiogenic factors production from transformed cells ${ }^{58,59}$ or to directly activate $\mathrm{EC},{ }^{60,61}$ indicating that multiple signals may lead to their differentia- 
$\mathbf{a}$
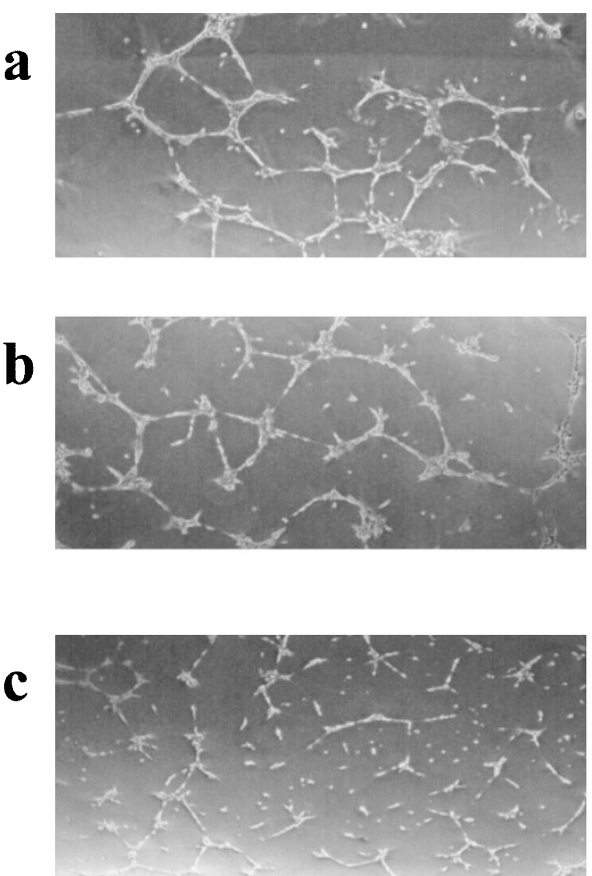
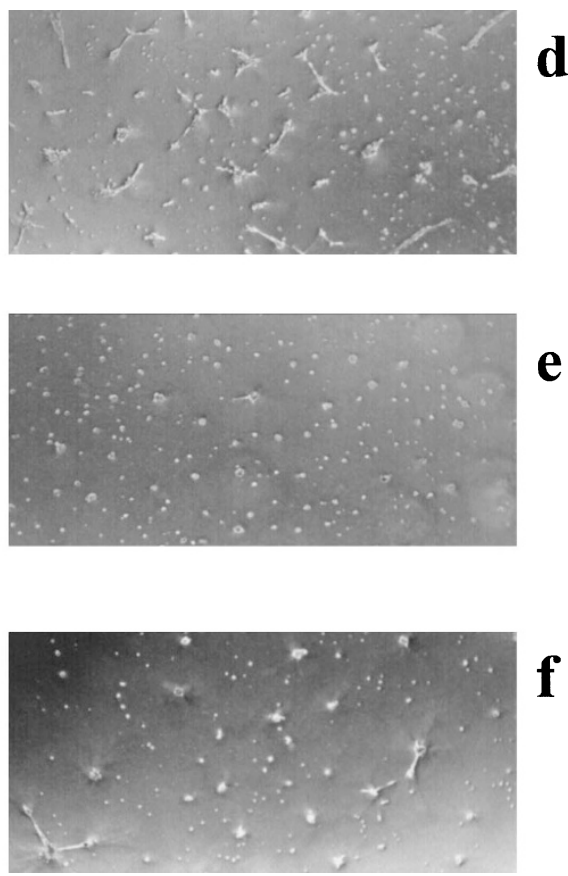

Figure 5 Neutralizing anti-FGF-2 antibodies inhibit E1A-induced BAEC differentiation on Matrigel. Transfected BAEC were plated on Matrigel $48 \mathrm{~h}$ after transfection, cultured in DMEM $1 \%$ FCS and pictures were taken $24 \mathrm{~h}$ after plating. A network of TS was evident in E1A 13S-transfected cells plated with control antibodies (panel b), while it was abolished in the presence of neutralizing anti-FGF-2 antibodies (panel e). Mock transfected cells differentiated poorly in the presence of control antibodies (panel d). Mock transfected cells in the presence of $10 \mathrm{ng} / \mathrm{ml}$ recombinant FGF-2 (panel c) or $10 \mathrm{ng} / \mathrm{ml}$ recombinant FGF-2 and neutralizing anti-FGF-2 antibodies (panel f) are shown, indicating that the specific antibodies inhibit TS induced by recombinant FGF-2. Mock transfected cells cultured in $10 \% \mathrm{FCS}$, as positive control of TS formation, are also shown (panel a). Pictures were taken at $50 \times$ magnification. Similar results were obtained in three independent experiments

tion. To investigate further the mechanisms of EC activation, adenovirus wtE1A proteins and the non-functional mutant dl646N were transiently transfected in primary BAEC. Wild type E1A-transfected EC differentiated in TS markedly faster than controls ( 3 vs $8 \mathrm{~h}$ shown in Figure 1). Interestingly, wtE1A overexpression increased FGF-2 and MMP-9 mRNA and protein levels (Figures 3 and 4) and significantly stimulated BAEC migratory and invasive capacity (Figure 2). Therefore we speculated that activation of an autocrine/ paracrine growth factor-dependent loop might underlie the observed biological effects, as a consequence of FGF-2 induction. FGF-2 is known to stimulate secretion of matrix degrading proteins in both endothelial and smooth muscle cells ${ }^{62,63}$ and this may explain the MMP-9 increase observed in wtE1A-transfected cells. In fact, anti-FGF-2 neutralizing antibodies reduced the amount of MMP-9 released in the CM of transfected BAEC (Figure 4C) however they did not influence the migration/invasion capacity of transfected cells (not shown). This result is in agreement with the evidence that the intracellular FGF-2, not sensitive to neutralizing antibodies present in culture medium, plays a role in the regulation of the migration/invasion process. ${ }^{64,65} \mathrm{E} 1 \mathrm{~A}$ overexpression increased the steady-state level of FGF-2 mRNA (Figure 3D) thus indicating the possible activation of either RNA transcription and/or stabilization. Accordingly, Western blot analysis indicated that the secretory $18 \mathrm{kDa}$ FGF-2 isoform is increased in the CMs of wtE1A-transfected cells (Figure 3B). In the same conditions, the intracellular content of LMW or HMW FGF-2 isoforms was not significantly changed (Figure $3 C$ ), thus indicating that, besides the increased mRNA levels, the release or mobilization of the $18 \mathrm{kDa}$ protein might be specifically stimulated by E1A. In agreement with this hypothesis, Barillari et al. recently described that a different viral protein, the HIV product TAT, facilitates the mobilization of membrane-bound FGF-2 in endothelial cells. ${ }^{66}$ While the molecular mechanisms remain to be elucidated, taken together, our observations suggest that forced expression of E1A modulates FGF-2 expression at multiple levels.

E1A is known to mimic growth factors in different cell types stimulating proliferation in the absence of serum or inducing protection from apoptosis under certain conditions..$^{50,52,67}$ Remarkably, the E1A functional homolog SV40 large T antigen has been shown to modulate intracellular signaling by directly interacting with the universal tyrosine kinase substrate protein $s h c^{32}$ thus reproducing a growth factordependent effect targeting proliferating stimuli to the nucleus. $\mathrm{E} 1 \mathrm{~A}$ and large $\mathrm{T}$ antigen are known to recognize common intracellular targets. ${ }^{68-71}$ Therefore, although direct evidences are lacking, we speculated that $\mathrm{E} 1 \mathrm{~A}$, similarly to large $\mathrm{T}$ antigen, might interact with some signalingintervening molecules, to achieve EC activation and FGF-2 production. Further experiments are now in progress to elucidate this point.

To assess the biological relevance of FGF-2 production, transfected cells were plated on Matrigel in the presence of anti-FGF-2 antibodies and complete inhibition of TS formation was achieved (Figure 5). Thus, we concluded 
that release of FGF-2 plays a relevant role in the $E C$ differentiation induced by wtE1A, while an additional intracrine effect of FGF-2 can not be excluded. Other studies have shown that $\mathrm{E} 1 \mathrm{~A}$ - immortalized or transformed endothelial cells still required exogenous FGF-2 to proliferate and/or differentiate. ${ }^{72,73}$ Results of those studies are not comparable with the current study since: (a) cells were from microvascular endothelium; (b) cells were evaluated only after a long period of selection at the end of which, at least in one case, ${ }^{72} \mathrm{E} 1 \mathrm{~A}$ expression could not be detectable any further; (c) all assays were performed on immortalized or transformed cell lines; and (d) the production of endogenous FGF-2 was not tested.

A large body of literature describes the role that growth factors and growth factor-receptors play in endothelial cell growth and differentiation. The present work may expand the knowledge about the role of oncogenes in this field. Unraveling the role of oncogenes in angiogenesis may contribute to design more efficient anti-angiogenic and antitumor therapeutic strategies.

\section{Materials and Methods}

\section{Cell isolation and culture}

Thoracic aortas of young calves were removed aseptically at the abattoir and stored on ice in phosphate buffered saline (PBS; Gibco BRL, Paisley, Scotland) with penicillin $(100 \mathrm{Ul} / \mathrm{ml})$, streptomycin $(100 \mu \mathrm{g} / \mathrm{ml})$ and amphotericin B $(2.5 \mu \mathrm{g} / \mathrm{ml})$. The aortas were then washed with Hanks' balanced salt solution (Hyclone Inc., Logan, UT, USA), opened longitudinally and incubated in Hanks' solution containing collagenase II (Sigma Chemical Co, St Louis, MO, USA) at $37^{\circ} \mathrm{C}$. After $30 \mathrm{~min}$ BAEC were removed by scraper and resuspended in fresh Hanks' solution, then resuspended in Dulbecco's modified Eagle's medium (DMEM; Hyclone Inc.) containing $20 \%$ fetal calf serum (FCS; Hyclone Inc.), and finally plated. BAEC were grown in DMEM supplemented with $10 \% \mathrm{FCS}, 100 \mathrm{UI} / \mathrm{ml}$ penicillin, $100 \mu \mathrm{g} / \mathrm{ml}$ streptomycin, $0.01 \mathrm{mg} / \mathrm{ml}$ glutamine and maintained at $5 \% \mathrm{CO}_{2}$ in an incubator at $37^{\circ} \mathrm{C}$. All experiments were performed with BAEC at passage between 2 and 6 . Purity of the cell population was assessed as previously described. ${ }^{74}$ Cells were incubated in fresh culture medium containing acetylated low density lipoprotein labeled with $10 \mu \mathrm{g} / \mathrm{ml}$ of $1,1^{\prime}$-dioctadecyl-3,3,3',3'-tetramethylindo-carbocyanine perchlorate (Biomedical Technologies Inc., Stoughton, MA, USA). After $4 \mathrm{~h}$ cells were washed and positive cells were counted by fluorescence microscopy. Purity was always $\geqslant 95 \%$.

\section{Plasmids and transfections}

Expression vectors for E1A $12 \mathrm{~S}$ and E1A $13 \mathrm{~S}$ and the E1A mutant dl646N, previously described, ${ }^{75-78}$ were kindly provided by $\mathrm{Dr}$. A Felsani (ITBM, CNR, Italy). Both pUC 19 and/or pcDNA3 were used as control plasmids (Clontech Laboratories Inc., Palo Alto, CA, USA; Invitrogen Corporation, Carlsbad, CA, USA). EC transfection was carried out on $80 \%$ confluent cells in $60-\mathrm{mm}$ plastic dishes using Dotap (Boehringer Mannheim, Indianapolis, IN, USA) according to the manufacturer's instructions. Cells (approximately $8 \times 10^{5}$ for each dish) were incubated with $30 \mu \mathrm{g}$ Dotap $/ 10 \mu \mathrm{g}$ DNA in serum-free medium overnight. Then the medium was replaced with fresh culture medium. Transfection efficiency was evaluated by X-Gal staining for each experiment and was always $\geqslant 30 \%$.

\section{Differentiation assay}

Two hundred microliters of Matrigel (Collaborative Research, Inc., Waltham, MA, USA) (12 mg/ml) were applied onto 24-well culture plates and incubated at $37^{\circ} \mathrm{C}$ for $60 \mathrm{~min}$. Cells, harvested by trypsin treatment $48 \mathrm{~h}$ after transfection, were seeded $\left(8 \times 10^{4}\right.$ transfected cells in $1 \mathrm{ml}$ fresh culture medium) on Matrigel-coated wells. The phenotypic changes of EC and the appearance of TS were monitored $0,2,3,4,5,6,8$ and $24 \mathrm{~h}$ after plating by phase contrast microscopy. TS were counted manually under a $100 \times$ magnification.

Goat neutralizing anti-FGF-2 antibody (R\&D System Europe Ltd; Abington, UK) was added at $500 \mathrm{ng} / \mathrm{ml}$ after plating cells on Matrigel, to block FGF-2. Normal goat serum (Zymed Laboratories Inc., South San Francisco, CA, USA) was used as control. Recombinant FGF-2 (Gibco) was used at $10 \mathrm{ng} / \mathrm{ml}$.

\section{Migration/invasion assays}

Migration/invasion assays were performed $48 \mathrm{~h}$ after transfection by the modified Boyden chamber assay. ${ }^{79}$ For migration assay, uncoated polycarbonate filters (12 $\mu \mathrm{m}$ pore diameter; Nucleopore Costar Scientific Corporation, Cambridge, MA, USA) were used. For invasion assay, filters were coated with $50 \mu \mathrm{l}$ of Matrigel $(0.3 \mathrm{mg} / \mathrm{ml})$. Boyden chambers were assembled by adding DMEM $1 \%$ FCS to the lower chamber as chemoattractant. BAEC $\left(2 \times 10^{5}\right)$ in DMEM containing $0.1 \%$ bovine serum albumin (BSA) were added to the upper chamber in a final volume of $850 \mu \mathrm{l}$. Boyden chambers were then incubated for $5 \mathrm{~h}$ at $37^{\circ} \mathrm{C}$ in a $5 \% \mathrm{CO}_{2}$ atmosphere and cells were counted at the optical microscope. Ten fields in each filter were evaluated at $400 \times$ magnification and all experiments were run in triplicate.

\section{ELISA test}

ELISA Kits (Quantikine, R\&D Import Export, Minneapolis, MN, USA) were used to measure FGF-2 and VEGF levels in cell culture supernatant, $48 \mathrm{~h}$ after transfection, according to the instructions. Supernatants were concentrated ten times by concentrators (Centricon tubes, Amicon Inc., Beverly, MA, USA) with a $1 \times 10^{4}$ Dalton molecular weight cut-off.

\section{Western blotting}

BAEC were washed $36 \mathrm{~h}$ after transfection and incubated for $24 \mathrm{~h}$ with serum-free medium. Conditioned media were collected and tenfold concentrated in Centricon tubes. Total cell lysates were prepared $48 \mathrm{~h}$ after transfection by lysing and scraping cells off the culture plate with $10 \mathrm{mM}$ Tris- $\mathrm{HCl}, \mathrm{pH} 6.8,0.4 \mathrm{mM}$ EDTA, 2\% SDS, leupeptin, aprotinin and antipain (10 $\mu \mathrm{g} / \mathrm{ml}$ each); $1 \mathrm{mM}$ phenylmethylsulfonyl fluoride and the following phosphatase inhibitors: $10 \mathrm{mM}$ sodium fluoride, $0.4 \mathrm{mM}$ sodium orthovanadate and $10 \mathrm{mM}$ pyrophosphate. Both conditioned media and cell lysates were electrophoresed in SDS-15\% polyacrylamide minigel under reducing conditions. Gels were then blotted to a polyvinylidene difluoride membrane (Immobilon P; Millipore Corp., Waters Chromatography, Bedford, MA, USA) for $1.5 \mathrm{~h}$ at $250 \mathrm{~mA}$. The membrane was then incubated with $5 \%$ skim milk (Carnation; Nestlé Food Co., Glendale, CA, USA) in PBS with $0.1 \%$ Tween (J.T. Baker, Milano, Italy) for $1 \mathrm{~h}$. FGF-2 was detected by incubating the membrane with $0.2 \mu \mathrm{g} / \mathrm{ml}$ of antibody anti-human FGF-2 (anti FGF-2; Santa Cruz Biotechnology, Inc.) overnight at $4^{\circ} \mathrm{C}$. Human recombinant FGF-2 (Life Technologies, Milano, Italy), loaded in the same minigel, was used as positive control. After incubation with horseradish peroxidase conjugated donkey anti-rabbit IgG $(1: 10000)$ for $1 \mathrm{~h}$ (Amersham Life 
Science, Buckinghamshire, UK), immune complexes were detected with the chemioluminescence ECL detection system (Amersham Life Science) by exposure to autoradiographic films (Sigma Aldrich s.r.l., Milano, Italy).

\section{Northern blotting}

Total RNA was isolated using TRIZOL Reagent (Life Technologies). Samples were processed following the manufacturer's protocol. Gels were blotted to a neutral nylon transfer membrane (Schleicher \& Schuell, Keene, $\mathrm{NH}$, USA). Northern-blot was prehybridized in hybridization buffer containing 50\% formamide (Sigma Aldrich), 10\% dextran sulfate (Sigma Aldrich), 1\% SDS (Sigma Aldrich), 1.2 M NaCl (Sigma Aldrich), sonicated salmon sperm (Stratagene, La Jolla, CA, USA), at $42^{\circ} \mathrm{C}$ for $4 \mathrm{~h}$. Hybridization was preformed overnight in prehybridization buffer containing $10^{6}$ c.p.m. $/ \mathrm{ml}$ of ${ }^{32} \mathrm{P}$-labeled fulllength cDNA probe encoding human FGF-2 (kindly provided by Professor M Presta). Filter was first washed in $2 \times$ SSC $0.1 \%$ SDS at room temperature, then in $0.5 \times \mathrm{SSC} 0.1 \% \mathrm{SDS}$ at $50^{\circ} \mathrm{C}, 0.2 \times \mathrm{SSC}$ $0.1 \%$ SDS at $50^{\circ} \mathrm{C}, 0.1 \times \operatorname{SSC} 0.1 \%$ SDS at $65^{\circ} \mathrm{C}$. Filters were exposed on Kodak Biomax MS Films.

\section{Zymography}

Cells were incubated for $24 \mathrm{~h}$ in serum-free medium and collected $60 \mathrm{~h}$ after transfection. Gelatin-degrading proteinases secreted into the culture medium by EC were analyzed by non-reducing sodium dodecyl sulfate-polyacrylamide gel electrophoresis in $9 \%$ gels containing $0.1 \%(\mathrm{wt} / \mathrm{vol})$ porcine gelatin (Sigma Chemical Co). After electrophoresis, gelatinases were renaturated by incubation at room temperature for $1 \mathrm{~h}$ in $2.5 \%$ ( $\mathrm{vol} / \mathrm{vol}$ ) Triton $\mathrm{X}-100$ and then at $37^{\circ} \mathrm{C}$ for $18 \mathrm{~h}$ in $50 \mathrm{mM}$ Tris- $\mathrm{HCl}(\mathrm{pH} 7.5)$ containing $0.2 \mathrm{M} \mathrm{NaCl}, 5 \mathrm{mM} \mathrm{CaCl} 2$ and $0.02 \%$ Brij 35 (wt/vol; Sigma Chemical Co). Gels were stained for $2 \mathrm{~h}$ with $0.5 \%$ Coomassie brilliant blue G-250 (Sigma Chemical Co) and destained for $1 \mathrm{~h}$ in $30 \%$ methanol, 10\% acetic acid. Active metalloproteinases (MMPs) degraded gelatin giving white bands against the blue background. Computer assisted densitometric analysis was performed using Gel Doc 1000 apparatus and Molecular Analyst Software (Bio-Rad, Hercules, CA, USA). Goat neutralizing anti-FGF-2 antibody (R\&D System Europe Ltd) or normal goat serum (Zymed) were added at $500 \mathrm{ng} / \mathrm{ml}$, during the $24 \mathrm{~h}$ incubation period in serum free medium.

\section{RNA isolation, reverse transcription (RT), PCR and Northern analyses}

Total RNA was isolated from $10^{6}$ cells $48 \mathrm{~h}$ after transfection using the High pure RNA isolation Kit (Boehringer Mannheim) and was quantified by measuring absorbance at $260 / 280 \mathrm{~nm}$. RT-PCR was conducted with RT - PCR kit (Stratagene, La Jolla, CA, USA) to detect MMP-9 mRNA. Primers specific for the bovine MMP-9 gene sequence (GENE BANK accession number X78324) were designed. The forward primer sequence consisted of $5^{\prime}$ ACC ACT ACC ACC ACC GAA CC $3^{\prime}$ while the reverse primer sequence was $5^{\prime}$ CGC CCA GAG AAG AAG AAA AT 3; they were synthesized to amplify the MMP-9 gene from nucleotide 1378 to nucleotide 1756 . The synthesis of the first-strand cDNA with reverse transcriptase was performed using oligo dt primers. The amplification of the first-strand cDNA using the polymerase chain reaction was carried out with 1 unit Taq DNA polymerase (Perkin Helmer, Foster City, CA, USA) and PCR buffer (Perkin Helmer) containing $1.5 \mathrm{mM} \mathrm{MgCl}_{2}$. Each sample was amplified in a thermal cycler by 40 repeat cycles at $94^{\circ} \mathrm{C}$ for $2 \mathrm{~min}, 55^{\circ} \mathrm{C}$ for $1 \mathrm{~min}$ and $72^{\circ} \mathrm{C}$ for $1 \mathrm{~min}$.
Computer assisted densitometric analysis was performed using Gel Doc 1000 apparatus and Molecular Analyst Software (Bio-Rad, Hercules, CA, USA).

\section{Statistical analysis}

The STATVIEW SE+GRAPHICS software (ABACUS CONCEPT, Berkley, CA, USA) was used to perform statistical analyses and Anova tests. A $P$ value equal or lower than 0.05 was considered significant.

\section{Acknowledgments}

We thank A Felsani for generously providing E1Adl646N mutant plasmid, and $\mathrm{M}$ Crescenzi and $\mathrm{F}$ Bussolino for helpful discussions. We also thank M Helmer-Citterich for technical support. This work was partially supported by EU grant BIOMED BMH4 96-1160 and AIRC grant awarded to MC Capogrossi. A Felici is a recipient of a fellowship from Fondazione Italiana per la Ricerca sul Cancro (FIRC).

\section{References}

1. Arnold F and West DC (1991) Angiogenesis in wound healing. Pharmacol. Ther. 52: $407-422$

2. Folkman J and Shing Y (1992) Angiogenesis. J. Biol. Chem. 267: 10931-10934

3. Capogrossi MC and Passaniti A (1997) Angiogenesis in the lung. In THE LUNG: Scientific Foundations. Crystal RG and West JB, eds. (Philadelphia: LippincottRaven Publishers) pp. 2629-2645

4. Folkman J (1995) Angiogenesis in cancer, vascular, rheumatoid, and other diseases. Nat. Med. 1: 27-31

5. Bussolino F, Mantovani A and Persico G (1997) Molecular mechanisms of blood vessel formation. Trends Biochem. Sci. 22: 251-256

6. Brooks PC, Clark RA and Cheresh DA (1994) Requirement of vascular integrin alpha $v$ beta 3 for angiogenesis. Science 264: $569-571$

7. FriendlanderM, Brooks PC, Shaffer RW, Kinkaid CM, Varner JA and ChereshDA (1995) Definition of two angiogenic pathways by distinct alpha $v$ integrins. Science 270: 1500-1502

8. O'Reilly MS, Boehm T, Shing Y, Fukai N, Vasios G, Lane WS, Flynn E, Birkhead JR, Olsen BR and Folkman J (1997) Endostatin: an endogenous inhibitor of angiogenesis and tumor growth. Cell 88: 277-285

9. Folkman J and Klagsburn M (1987) Angiogenic factors. Science 235: 442-447

10. Presta M and Rifkin DB (1988) New aspects of blood vessel growth: tumor and tissue-derived angiogenesis factors. Haemostasis 18: 6-17

11. Risau W (1990) Angiogenic growth factors. Prog. Growth Factor Res. 2: 71-79

12. Klagsburn M and D'Amore PA (1991) Regulators of angiogenesis. Annu. Rev. Physiol. 53: 217-239

13. Battegay EJ (1995) Angiogenesis: mechanistic insights, neovascular diseases, and therapeutic prospects. J. Mol. Med. 73: 333-346

14. Sommer A, Brewer MT, Thompson RC, Moscatelli D, Presta M and Rifkin DB (1987) A form of human fibroblast growth factor with an extended amino terminus. Biochem. Biophys. Res. Comm. 144: 543-550

15. Prats H, Kaghad M, Prats AC, Klagsburn M, Lellias JM, Liazun P, Chalon P, TauberJP, Amalric F, Smith JA and CaputD (1989) High molecular mass forms of basic fibroblast growth factor are initiated by alternative CUG codons. Proc. Natl. Acad. Sci. U.S.A. 86 : $1836-1840$

16. Arnaud E, Touriol C, Boutonnet C, Gensac MC, Vagner S, Prats H and Prats AC (1999) A new 34-kilodalton isoform of human fibroblast growth factor 2 is cap dependently synthesized by using a non-AUG start codon and behaves as a survival factor. Mol. Cell. Biol. 19: 505-514

17. Moscatelli $D$ (1987) High and low affinity binding sites for basic fibroblast growth factor on cultured cells: absence of a role for low affinity binding in the stimulation of plasminogen activator production by bovine capillary endothelial cells. J. Cell. Physiol. 131: 123-130 
18. Lee PL, Johnson DE, Cousens LS, Fried VA and Williams LT (1989) Purification and complementary DNA cloning of a receptor for basic fibroblast growth factor. Science 245: 57-60

19. Dionne CA, Crumley G, Bellot F, Kaplow JM, Searfoss G, Ruta M, Burgess WH Jaye $M$ and Shlessinger J (1990) Cloning and expression of two distinct highaffinity receptors cross-reacting with acidic and basic fibroblast growth factor. EMBO J. 9: 2685-2692

20. Keegan K, Johnson DE, Williams LT and Hayman MJ (1991) Isolation of an additional member of the fibroblast growth factor receptor family, FGFR-3. Proc. Natl. Acad. Sci. U.S.A. 88: 1095-1099

21. Partanen J, Makela TP, Eerola E, Korhonen J, Hirvonen H, Claesson-Welsh L and Alitalo K (1991) FGFR-4, a novel acidic fibroblast growth factor receptor with a distinct expression pattern. EMBO J. 10: 1347-1354

22. Abraham JA, Mergia A, Whang JL, Tumolo A, Friedman J, Hjerrild KA, Gospodarowicz D and Fiddes JC (1986) Nucleotide sequence of a bovine clone encoding the angiogenic protein, basic fibroblast growth factor. Science 233 545-548

23. Mignatti $P$ and Rifkin DB (1991) Release of basic fibroblast growth factor, an angiogenic factor devoid of secretory signal sequence: a trivial phenomenon or a novel secretion mechanism? J. Cell. Biochem. 47: 201-207

24. Mignatti P, Morimoto T and Rifkin DB (1992) Basic fibroblast growth factor, a protein devoid of secretory signal sequence, is released by cells via a pathway independent of the endoplasmic reticulum-Golgi complex. J. Cell. Physiol. 151: $81-93$

25. Montesano R, VassalliJD, Baird A, Guillemin Rand Orci L (1986) Basic fibroblas growth factor induces angiogenesis in vitro. Proc. Natl. Acad. Sci. U.S.A. 83 7297-7301

26. Moscatelli D, Presta M and Rifkin DB (1986) Purification of a factor from human placenta that stimulates capillary endothelial cell protease production, DNA synthesis, and migration. Proc. Natl. Acad. Sci. U.S.A. 83: 2091-2095

27. Sato Y and Rifkin DB (1988) Autocrine activities of basic fibroblast growth factor: regulation of endothelial cell movement, plasminogen activator synthesis, and DNA synthesis. J. Cell. Biol. 107: 1199-1205

28. Sato Y, Shimada T and Takaki R (1991) Autocrinological role of basic fibroblast growth factor on tube formation of vascular endothelial cells in vitro. Biochem. Biophys. Res. Commun. 180: 1098-1102

29. Moses HL (1992) TGF-beta regulation of epithelial cell proliferation. Mol. Reprod. Dev. 32: $179-184$

30. Baserga R (1993) Gene regulation by IGF-I. Mol. Reprod. Dev. 35: 353-356

31. Zepter K, Haffner AC, Trefzer U and Elmets CA (1995) Reduced growth factor requirements and accelerated cell-cycle kinetics in adult human melanocytes transformed with SV40 large T antigen. J. Invest. Dermatol. 104: 755-762

32. Gottifredi V, Pelicci G, Munarriz E, Maione R, Pelicci PG and Amati P (1999) Polyomavirus large $T$ antigen induces alterations in cytoplasmic signalling pathways involving Shc activation. J. Virol. 73: 1427-1437

33. Jones N (1995) Transcriptional modulation by the adenovirus E1A gene. Curr. Top. Microbiol. Immunol. 199: 59-80

34. Flint J and Shenk T (1997) Viral transactivating proteins. Annu. Rev. Genet. 31 $177-212$

35. Dyson N and Harlow E (1992) Adenovirus E1A targets key regulators of cell proliferation. Cancer Surv. 12: 161-195

36. Peeper DS and Zantema A (1993) Adenovirus-E1A proteins transform cells by sequestering regulatory proteins. Mol. Biol. Rep. 17: 197-207

37. Moran E (1994) Cell growth control mechanisms reflected through proteinprotein interactions with the adenovirus E1A gene products. Semin. Virol. 5: $327-340$

38. Ludlow JW and Skuse GR (1995) Viral oncoprotein binding to pRB, p107, p130, and p300. Virus Res. 35: 113-121

39. Jansen-Durr P (1996) How viral oncogenes make the cell cycle. Trends Genet. 12: $270-275$

40. Condorelli Gand Giordano A (1997) Synergistic role of E1A-binding proteins and tissue-specific transcription factors in differentiation. J. Cell. Biochem. 67: 423431

41. Egan C, Bayley ST and Branton PE (1989) Binding of the Rb1 protein to E1A products is required for adenovirus transformation. Oncogene 4: 383-388

42. Whyte P, Buchkovich KJ, Horowitz JM, Friend SH, Raybuck M, Weinberg RA and Harlow E (1988) Association between an oncogene and an anti-oncogene: the adenovirus $\mathrm{E} 1 \mathrm{~A}$ proteins bind to the retinoblastoma gene product. Nature 14 $124-129$
43. Pines $\mathrm{J}$ and Hunter $\mathrm{T}$ (1990) Human cyclin $\mathrm{A}$ is adenovirus E1A-associated protein $p 60$ and behaves differently from cyclin $B$. Nature 23: 760-763

44. Ewen ME, Xing YG, Lawrence JB and Livingston DM (1991) Molecular cloning, chromosomal mapping and expression of the CDNA for p107, a retinoblastoma gene product-related protein. Cell 66: 1155-1164

45. Mayol X, Grana X, Baldi A, Sang N, Hu Q and Giordano A (1993) Cloning of a new member of the retinoblastoma gene family (pRb2) which binds to the $E 1 A$ transforming domain. Oncogene 8: 2561-2566

46. Eckner R, Ewen ME, Newsome D, Gerdes M, DeCaprio JA, Lawrence JB and Livingston DM (1994) Molecular cloning and functional analysis of the adenovirus E1A-associated $300-k D$ protein (p300) reveals a protein with properties of transcriptional adapters. Genes Dev. 8: 869-884

47. Barbeau D, Charbonneau R, Whalen SG, Bayley ST and Branton PE (1994) Functional interactions within adenovirus $\mathrm{E} 1 \mathrm{~A}$ protein complexes. Oncogene 9: $359-373$

48. Nevins JR (1995) Adenovirus E1A: transcription regulation and alteration of cell growth control. Curr. Top. Microbiol. Immunol. 199: 25-32

49. Nguyen M, Branton PE, Roy S, Nicholson DW, Alnemri ES, YehWC, Mak TW and Shore GC (1998) E1A-induced processing of procaspase-8 can occur independently of FADD and is inhibited by Bcl-2. J. Biol. Chem. 273: 3309933102

50. Quinlan MP, Sullivan N and Grodzicker T (1987) Growth factor(s) produced during infection with an adenovirus variant stimulates proliferation of nonestablished epithelial cells. Proc. Natl. Acad. Sci. U.S.A. 84: 3283-3287

51. Subramanian T, Kuppuswamy M, Nasr RJ and Chinnadurai G (1988) An Nterminal region of adenovirus $\mathrm{E} 1 \mathrm{~A}$ essential for cell transformation and induction of an epithelial cell growth factor. Oncogene 2: 105-112

52. Quinlan MP (1989) The Ad5 $12 S$ growth factor induces F9 cell proliferation and differentiation. Oncogene 4: 1051-1055

53. Baatout S (1997) Endothelial differentiation using Matrigel. Anticancer Res. 17: $451-455$

54. Pauly RR, Passaniti A, Crow M, Kinsella JL, Papadopoulos N, Monticone R, Lakatta EG and Martin GR (1992) Experimental models that mimic the differentiation and dedifferentiation of vascular cells. Circulation 86: III68- III73

55. Bussolino F, Mantovani A and Persico G (1997) Molecular mechanisms of blood vessel formation. Trends Biochem. Sci. 22: 251-256

56. Rifkin DB, Moscatelli D, Bizik J, Quarto N, Blei F, Dennis P, Flaumenhaft R and Mignatti P (1990) Growth factor control of extracellular proteolysis. Cell Differ. Dev. 32: $313-318$

57. Risau W (1997) Mechanisms of angiogenesis. Nature 386: 671-674

58. Costa M, Danesi R, Agen C, Di Paolo A, Basolo F, Del Bianchi Sand Del Tacca M (1994) MCF-10A cells infected with the int-2 oncogene induce angiogenesis in the chick chorioallantoic membrane and in the rat mesentery. Cancer Res. 54: $9-11$

59. Rak J, Filmus J, Finkenzeller G, Grugel S, Marme D and Kerbel RS (1995) Oncogenes as inducers of tumor angiogenesis. Cancer Metastasis Rev. 14: 263-277

60. WagnerEFand Risau W (1994) Oncogenes in the study of endothelial cell growth and differentiation. Semin. Cancer Biol. 5: 137-145

61. Arbiser JL, Moses MA, Fernandez CA, Ghiso N, Cao Y, Klauber N, Fran D, Brownlee M, Flynn E, Parangi S, Byers HR and Folkman J (1997) Oncogenic Hras stimulates tumor angiogenesis by two distinct pathways. Proc. Natt. Acad. Sci. U.S.A. 94: $861-866$

62. Tsuboi R, Sato Y and Rifkin DB (1990) Correlation of cell migration, cell invasion, receptor number, proteinase production and basic fibroblast growth factor levels in endothelial cells. J. Cell. Biol. 110: 511-517

63. Kenagy RD, Hart CE, Stetler-Stevenson WG and Clowes AW (1997) Primate smooth muscle cell migration from aortic explants is mediated by endogenous platelet-derived growth factor and basic fibroblast growth factor acting through matrix metalloproteinases 2 and 9. Circulation 96: 3555-3560

64. Davis MG, Zhou M, Ali S, Coffin JD, Doetschman T and Dorn II GW (1997) Intracrine and autocrine effects of basic fibroblast growth factor in vascular smooth muscle cells. J. Mol. Cell. Cardiol. 29: 1061-1072

65. Pasumarthi KB, Kardami E and Cattini PA (1996) High and low molecular weight fibroblast growth factor-2 increase proliferation of neonatal rat cardiac myocytes but have differential effects on binucleation and nuclear morphology. Evidence for both paracrine and intracrine actions of fibroblast growth factor-2. Circ. Res. 78: $126-136$ 
66. Barillari G, Sgadari C, Fiorelli V, Samaniego F, Colombini S, Manzari V, Modesti A, Nair BC, Cafaro A, Stürzl M and Ensoli B (1999) The Tat protein of human immunodeficiency virus Type-1 promotes vascular cell growth and locomotion by engaging the $\alpha 5 \beta 1$ and $\alpha \mathrm{v} \beta 3$ integrins and by mobilizing sequestered basic fibroblast growth factor. Blood 94: 663-672

67. Quinlan MP (1993) E1A 12S in the absence of E1B or other cooperating oncogenes enables cells to overcome apoptosis. Oncogene 8: 3289-3296

68. Magnusson G (1985) Recent progress in studies of polyomavirus tumour antigens. Exp. Cell. Res. 157: 1-7

69. Noble JC, Pan ZQ, Prives C and Manley JL (1987) Splicing of SV40 early premRNA to large $T$ and small $t$ mRNAs utilizes different patterns of lariat branch sites. Cell 50: 227-236

70. Pipas JM (1992) Common and unique features of T antigens encoded by the polyomavirus group. J. Virol. 66: 3979-3985

71. Pipas JM (1998) Molecular chaperone function of the SV40 large T antigen. Dev. Biol. Stand. 94: 313-319

72. Lauljainen T, Julkunen I, Haltia A, Knuutila S, Miettinen A and Holthofer H (1993) Establishment and characterization of a rat glomerular endothelial cell line. Lab. Invest. 69: 183-192

73. Roux F, Durieu-Traumann O, Chaverot N, Claire M, Mailly P, Bourre JM, Strosberg AD and Couraud PO (1994) Regulation of gamma-glutamyl transpeptidase and alkaline phosphatase activities in immortalized rat brain microvessel endothelial cells. J. Cell. Physiol. 159: 101-113
74. Netland PA, Zetter BR, Via DP and Voyta JC (1985) In situ labelling of vascular endothelium with fluorescent acetylated low density lipoprotein. Histochem. J. 17: $1309-1320$

75. Van Ormondt H, Maat J, De Waard A and Van der Eb AJ (1978) The nucleotide sequence of the transforming Hpal-E fragment of adenovirus type 5 DNA. Gene 4: $309-328$

76. Whyte P, Ruley HE and Harlow E (1988) Two regions of the adenovirus early region $1 \mathrm{~A}$ proteins are required for transformation. J. Virol. 62: 257-265

77. Whyte $P$, Williamson NM and Harlow E (1989) Cellular targets for transformation by the adenovirus E1A proteins. Cell 56: $67-75$

78. Routes JM, Li H, Bayley ST, Ryan S and Klemm DJ (1996) Inhibition of IFNstimulated gene expression and IFN induction of cytolytic resistance to natural killer cell lysis correlate with E1A-p300 binding. J. Immunol. 156: 1055-1061

79. Albini A, Iwamoto Y, Kleinman HK, Martin GR, Aaronson SA, Kozlowski JM and McEwan RN (1987) A rapid in vitroassay for quantitating the invasive potential of tumor cells. Cancer Res. 47: 3239-3245 